\title{
River discharge to the Baltic Sea in a future climate
}

\author{
Chantal Donnelly • Wei Yang • Joel Dahné
}

Received: 13 November 2012 / Accepted: 17 September 2013 / Published online: 17 November 2013

(C) The Author(s) 2013. This article is published with open access at Springerlink.com

\begin{abstract}
This study reports on new projections of discharge to the Baltic Sea given possible realisations of future climate and uncertainties regarding these projections. A high-resolution, pan-Baltic application of the Hydrological Predictions for the Environment (HYPE) model was used to make transient simulations of discharge to the Baltic Sea for a mini-ensemble of climate projections representing two high emissions scenarios. The biases in precipitation and temperature adherent to climate models were adjusted using a Distribution Based Scaling (DBS) approach. As well as the climate projection uncertainty, this study considers uncertainties in the bias-correction and hydrological modelling. While the results indicate that the cumulative discharge to the Baltic Sea for 2071 to 2100, as compared to 1971 to 2000, is likely to increase, the uncertainties quantified from the hydrological model and the bias-correction method show that even with a state-of-the-art methodology, the combined uncertainties from the climate model, bias-correction and impact model make it difficult to draw conclusions about the magnitude of change. It is therefore urged that as well as climate model and scenario uncertainty, the uncertainties in the bias-correction methodology and the impact model are also taken into account when conducting climate change impact studies.
\end{abstract}

\section{Introduction}

How discharge to the Baltic Sea will change is a significant uncertainty regarding future climate in the Baltic Sea region (Meier et al. 2006). For example, this is of particular interest when considering changes to salinity levels in the sea which has implications for the sea's unique ecosystem. Changes in precipitation $(P)$, temperature $(T)$ and evapotranspiration $(E)$ in a future climate affect generation of runoff $(R)$, and the resulting discharge, $(Q)$. Studies to date, including regional climate studies and impact studies on the catchment hydrology and Baltic Sea ecosystems were summarised in 2008 (BACC Author Team 2008). Previously published studies have predicted net changes in total Q to the Baltic Sea ranging from around -14 to + $33 \%$ (Graham 2004; Meier et al. 2006; Hansson et al. 2011; Hagemann et al. 2012). Nevertheless, methods used to make impact studies have progressed since the aforementioned studies for this region.

C. Donnelly $(\bowtie) \cdot$ W. Yang $\cdot$ J. Dahné

Swedish Meteorological and Hydrological Institute, 1 Folkborgsvägen, 60176 Norrköping, Sweden e-mail: Chantal.donnelly@gmail.com

W. Yang

e-mail: wei.yang@smhi.se

J. Dahné

e-mail: joel.dahne@smhi.se 
Previous estimates of total changes to $Q$ to the Baltic Sea have been taken directly from global climate models (GCMs) or regional climate models (RCMs) using simple water balance calculations from the climate model outputs (e.g. $P$ - E, e.g. IPCC 2001; Meleshko et al. 2004) or runoff output directly from climate models (e.g. Hagemann et al. 2009). Evaluations of GCM and RCM outputs show strong biases for present climate, such as overestimation of $P$ and Winter $T$ in parts of Northern Europe (Kjellström et al. 2010) and systematic overestimation of $E$ from RCMs for the Baltic Basin (Graham et al. 2007). Furthermore a large-scale calculation of mean annual $(P-E)$ has insufficient representation of hydrological storage in snow, groundwater, lakes and magazines to resolve seasonal and spatial differences. This has been handled by applying routing to RCM model outputs, e.g. Hagemann and Dumenil (1999) and Graham et al. (2007); however, these studies are still subject to the aforementioned biases from the climate models.

An alternative is statistical downscaling of air temperature atmospheric indices to total Q to the Baltic Sea (Hansson et al. 2011). Simplified extrapolation of this technique to future climates suggested 8-14\% reduction in total annual Q based on predicted increase in temperature of $3-5{ }^{\circ} \mathrm{C}$ for 2100 ; however changes in atmospheric indices in future climate were not considered. The regression model works well for the Northern and Southern Baltic region, but poorly in the Gulf of Finland where two large lakes result in a more complex system with lag and dampening effect.

To include the effects of routing and hydrological storage, hydrological models can be used. Graham (2004) set up the HBV model to calculate monthly inflows to the Baltic Sea, for four different climate projections using a delta-change method to account for biases in precipitation and temperature from climate models. This study was extended to 16 climate projections with predicted change in total Q ranging from $-8 \%$ to $26 \%$ (Meier et al. 2006). Recently Omstedt et al. (2012), showed results of two climate change scenarios corrected using delta-change to force a lumped conceptual hydrological model set-up for 82 rivers and 35 coastal areas for the Baltic Sea catchment. Both these projections also indicated increases in Q to the Baltic Sea.

State-of-the-art in simulating the impact of CC on Q for large river basins is similar to that described above and includes perturbing an observed forcing data set with a future climate change predicted by a GCM or RCM (Yukon River: Hay and McCabe 2010; Danube basin: Kling et al. 2012) or using raw RCM outputs (Colorado River: Gao et al. 2011). The deltachange method is a conventionally used approach when conducting CC impact studies. It is easy to implement; however it is unable to deal with covariance and the variability of weather variables in future climate (Graham et al. 2007), hence the need for bias correction (BC) techniques. Most state-of-the-art catchment scale studies use more advanced BC methods for correcting RCM outputs to force offline hydrological models (e.g. Olsson et al. 2011; Hurkmans et al. 2010; Fowler et al. 2007); however few of these consider the uncertainties arising from $\mathrm{BC}$ or the HM.

Large-scale hydrological models (spanning multiple catchments) and land-surface schemes are emerging for use in CC impact studies (e.g. Van Vliet et al. 2012) along with bias-corrected forcing data. Although such models cannot reproduce $\mathrm{Q}$ to the performance levels of catchment scale models simultaneously in all catchments within the domain, they allow for studies over large regions (e.g. Arnel 1999; Van Vliet et al. 2012). A recent global scale climate change study where eight global hydrological models (GHMs) were forced by three GCMs and two emissions scenarios suggested that uncertainty in Q was relatively constrained for the Baltic Sea basin (Hagemann et al. 2012). Nevertheless, the predicted variation in change to Baltic Sea Q predicted by the 8 GHMs ranged from around $-3 \%$ to + $33 \%$ of today's $\mathrm{Q}$, which is larger than the uncertainty shown by previous estimates based on a single hydrological model (e.g. Meier et al. 2006). 
This new, regional study for the Baltic Sea basin uses a pan-Baltic application of the HYPE model (Lindström et al. 2010) to simulate the effects of a mini-ensemble of five biascorrected climate projections representing variations of business-as-usual conditions on freshwater influxes to the Baltic Sea. New to this study is that transient estimates of Q to the Baltic Sea are made using bias-corrected RCM forcing in a large-scale (multi-basin) hydrological model, Balt-HYPE, with sufficient resolution to respond to the spatial variation in climate impacts. Rather than simulating a large ensemble such as done in previous studies for the region (e.g. Meier et al. 2006), emphasis was put on updating the methodology used to estimate $\mathrm{Q}$ change to the Baltic Sea and investigating relative uncertainties. The impact of uncertainty due to the hydrological model is not usually accounted for in climate change impact studies (Hagemann et al. 2012). Hagemann et al. (2012) addressed this by using an ensemble of GHMs, but in this study, the magnitude of the uncertainty from a single hydrological model and the $\mathrm{BC}$ methodology is discussed in relation to the spread of results for the simulated climate scenarios. The methods shown here could be used to estimate changes to and uncertainties in Q for other large scale river basins and the basins of other enclosed seas such as the Black Sea or the Mediterranean Sea, where few similar studies for the whole sea's catchments have been made.

\section{Data and methods}

\subsection{Hydrological model and its setup}

A high-resolution, process based hydrological and nutrient flux model was set up for the Baltic Sea catchment using the HYPE model (Lindström et al. 2010), a semi-distributed, process based hydrological and nutrient model. It shares some similarities to the HBV (Bergström 1976), VIC (Liang et al. 1994) and SWAT (Arnold et al. 1994) models. The major hydrological processes simulated by the model are snow accumulation and snowmelt, evapotranspiration, surface runoff, macropore flow, tile drainage, groundwater outflow from soil layers, routing through rivers and retention and outflow from lakes and reservoirs, both natural and regulated. Calculations are made for unique Soil and Land Cover classes (SLC classes) at the subbasin scale; flow is then routed between subbasins. The model input data sources are summarised in Table 1. The model was set up with a median subbasin resolution of $325 \mathrm{~km}^{2}$. Daily river discharge data from the BALTEX (BHDC 2009) and GRDC (2009) databases was used to calibrate and validate parameters describing hydrological processes. The period 1980 to 2004 was used for both calibration and validation because this was the period of availability of the hindcast forcing data.

Calibration of the model made use of the concept of Representative Gauged Basins (RGBs, Strömqvist et al. 2012). Groups of RGBs for each soil-type had (a) limited effect of lakes, i.e. $<1 \%$ lake area, and (b) dominance of soil-type of interest, i.e. at least $>50 \%$ of the gauged basin area. A simple manual calibration was then done by optimising five parameters (for field capacity, effective porosity, recession in soil layers, and tile drains) for each group, i.e. for the coarse grained soils RGB, parameters were optimised by looking graphically at performance and at the correlation coefficient $(r)$, relative error (RE) and Nash-Sutcliffe error (NSE) simultaneously for the group. Because a group of basins is calibrated simultaneously, there is a compromise in model performance at a single site, to optimise performance for the whole group. Nevertheless, these compromises are commonly accepted in large-scale modelling (e.g. Vörösmarty et al. 1989; Arnel 1999). In total 35 stations were used in calibration.

To determine whether the calibrated model was capable of reproducing spatial and temporal variability in Q to the Baltic Sea, model performance at 31 stations near the Baltic coastline was 
Table 1 Summary of Balt-HYPE model data inputs and set up

\begin{tabular}{ll}
\hline Data type & Details (source) \\
\hline Areal extent & 1,8 million km² \\
Median Subbasin Resolution & $325 \mathrm{~km}^{2}$ \\
No. Subbasins & 5128 \\
Topography/routing & Hydro1K (USGS 2000) \\
Precipitation and & ERAMESAN 1980-2004, Jansson \\
$\quad$ Temperature Data & et al. (2007), Resolution=11 km. \\
Landcover & Globcover 2000 (GLC 2009) \\
Soil types & European Soils Database (JRC 2006) \\
Discharge measurements & GRDC (GRDC 2009), BALTEX \\
& (BHDC 2009) \\
\hline
\end{tabular}

evaluated by looking at the monthly NSE, RE and the Pearson correlation coefficient ( $r$ ) at each station. Even if a bias (indicated by $R E$ ) exists at a station, it is the relative change in $Q$ which is of interest in this climate change study, so the correlation coefficient $(r)$ gives a relevant measure of the model's ability to reproduce the processes that drive variability in the catchment. Because this study focuses on change to total Q to the Baltic Sea, the reproduction of the seasonal and total Q to the Baltic Sea was also compared with observations and previous studies.

\subsection{Bias correction methodology}

Distribution-Based Scaling aims to adjust systematic bias in GCM/RCM outputs whilst preserving the temporal variability in meteorological variables resulting from climate projections. Comparable to other well-known quantile-mapping methods (Piani et al. 2010; Themeß1 et al. 2010), DBS implements parametric distributions to describe the variables of interest to correct the variable outside the reference period. Additionally, co-variation between $\mathrm{P}$ and $\mathrm{T}$ is taken into consideration.

Adjusting precipitation is a two-step process: 1) days with precipitation $<$ threshold are changed to $0 \mathrm{~mm}$ to match the observed percentage of wet days (RCMs tend to generate spurious 'drizzle'); 2) precipitation is transformed to match the observed frequency distribution. Normal and extreme precipitation events are separated by a 95th percentile value calculated from the whole precipitation series. Their main properties are captured by implementing a double-gamma distribution. Considering the dependency between precipitation and temperature, the systematic bias in temperature is adjusted conditioned on the wet or dry state of the day. The conditioned temperature is then fitted to a normal distribution whose distribution parameters are smoothed using a 15-day moving window and described by Fourier series. Details can be found in Yang et al. (2010).

\subsection{Future climate projections}

The calibrated and validated model, Balt-HYPE, was then used to simulate the impacts of a mini-ensemble of five downscaled climate projections. These projections were chosen by Meier et al. (2011) to represent two high emissions scenarios (business-as-usual), aspects of GCM uncertainty and those GCMs that performed best for the Baltic Sea region. Four of the five projections were downscaled using RCAO to $25 \mathrm{~km}$ (Meier et al. 2011) while the fifth was regionally downscaled to $50 \mathrm{~km}$ using the RCA3 model (Kjellström et al. 2010). The scenarios chosen are denoted as RCAOE5A1B ${ }_{1}, \mathrm{RCAOE}_{\mathrm{A}} \mathrm{BB}_{3}, \mathrm{RCAOE} 5 \mathrm{~A} 2, \mathrm{RCAOH} 3 \mathrm{~A} 1 \mathrm{~B}$ and 
RCA3E5A1B 3 where E5 and H3 denote the ECHAM5 (Jungclaus et al. 2006) and Hadley CM3 (Collins et al. 2010) GCMs respectively, and A1B and A2 denote emissions scenarios from the IPCC representing rapid economic growth and a differentiated world, respectively (Nakicenovic and Swart 2000). Roughly this represents business-as-usual. Although this ensemble is not large enough to constrain all the climate model or emissions uncertainty, it is useful to analyse some of the sources of uncertainty and relate hydrological model uncertainty to climate model uncertainty.

Five transient, daily simulations from 1971 to 2100 (with spin-up 1961 to 1970) were made. To facilitate comparison of the projections with each other and previous studies, mean annual values of $\mathrm{P}, \mathrm{T}$, local runoff $(\mathrm{R})$ and $\mathrm{Q}$ were calculated for a reference period (1971 to 2000) and a future period (2071 to 2100). Hydrological changes were then defined as the difference between mean annual values for the future period (called P2) and the reference period (called P1). Percent changes were calculated as this change divided by the P1 mean value $\times 100 \%$.

\section{Results}

\subsection{Model validation}

For stations to sea, median values of performance across the 31 stations were: $R E$ : $-2.0 \%$, daily $r$ : 0.78 and monthly NSE: $0.51 \%$. Most ( $>75 \%$ ) stations could be simulated to within $15 \% R E$, $r>0.7$ and NSE $>0.4$. Spatial variations in performance are shown in Fig. 1 . Spread of results across stations can be attributed to limitations in input data and calibration when setting up a large-scale hydrological model, particularly biases in the gridded precipitation data and ability to simulate anthropogenic water management (e.g. poorer NSE in regulated rivers). Total simulated Q to the Baltic Sea, $15,609 \mathrm{~m}^{3} / \mathrm{s}$, compared well to that estimated by Bergström and Carlsson (1994) who estimated a total Q of $15,310 \mathrm{~m}^{3} / \mathrm{s}$ based on observations in filled with simulated data from the HBV model. Seasonal distribution of total Q to the Baltic Sea was also well reproduced by the model (Fig. 1d). There is a small overestimation of runoff between June and December and an underestimation for January to April. Figure 2 shows simulated and observed flow for two averagely performing rivers in the model, the Kalix River and the Oder River.

\subsection{Bias-correction of the climate projections}

The DBS bias-correction (BC) was tuned for the period 1980 to 2004. Table 2 shows the mean annual basin precipitation during the tuning period for each of the raw and corrected ensemble members and the discharge using corrected precipitation. There is still a small bias (up to $+/-3 \%$ ) in the total corrected precipitation across the basin which results in biases in Q of up to $7 \%$. Nevertheless, this is much less than the biases had the raw climate data been used (26 to $43 \%$ ) and it is also seen that DBS significantly improves the distribution of precipitation and resulting discharge events (e.g. for RCAOE5A1B3, Fig. 3). This result was representative for all the scenarios.

\subsection{Projections of future discharge}

All projections indicate increases in average Q to the Baltic Sea ranging from $1 \%$ to $14 \%$ by the end of the century with an ensemble average of $+8 \%$ (Table 3). For all projections seasonal dynamics of $\mathrm{Q}$ to the Baltic Sea are expected to change considerably compared to 

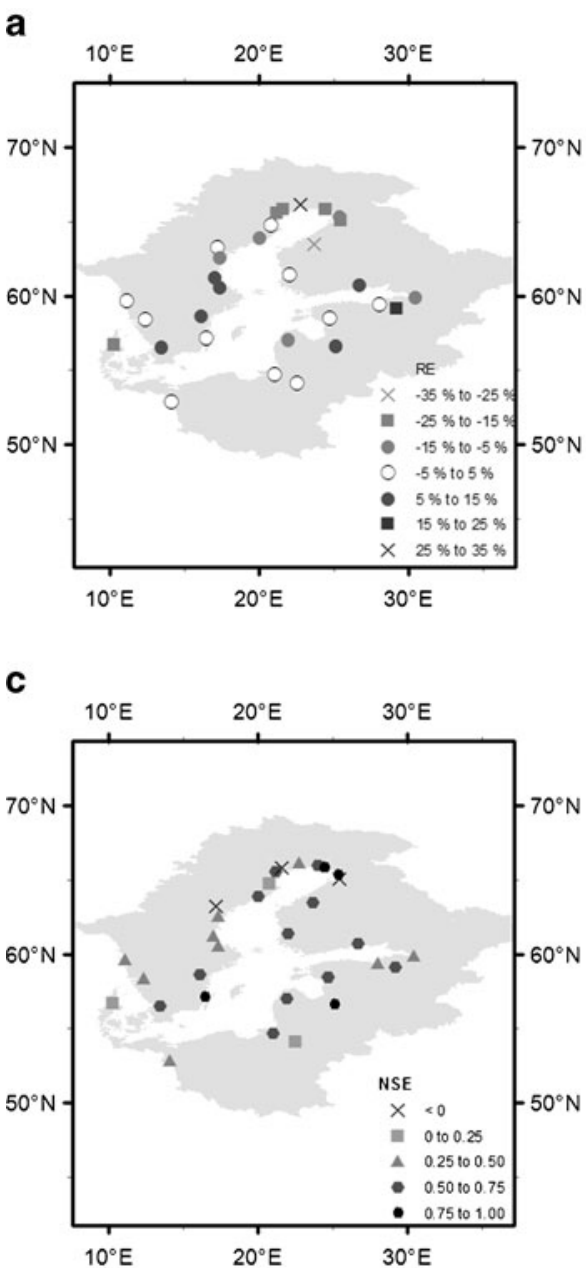

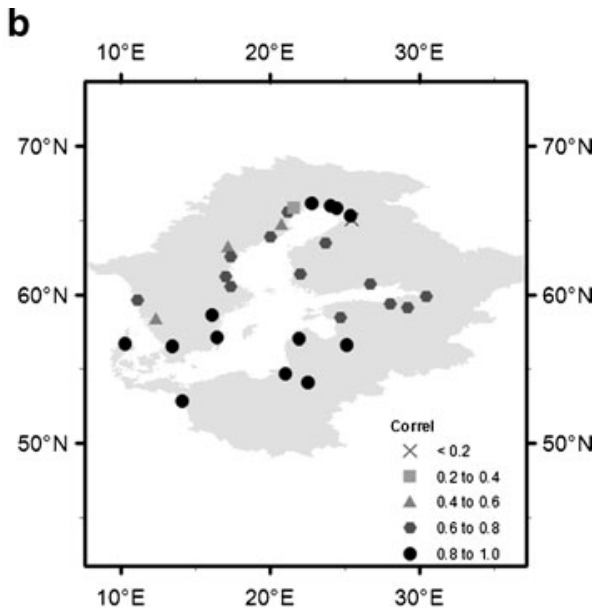

d

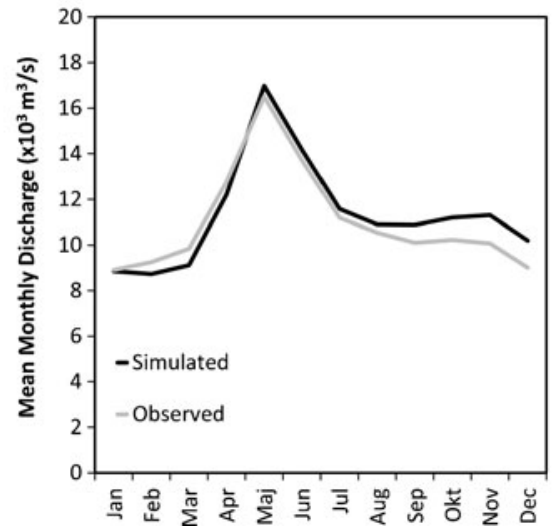

Fig. 1 Validation of Balt-HYPE discharge. (a) relative error, $R E$ (b) daily correlation coefficient, r, (c) monthly Nash-Sutcliffe Efficiency, NSE, (d) observed and simulated mean monthly discharge distribution to Baltic Sea where mean is calculated only for locations with observed discharge to sea for the period $1980-2005$

today's pattern (Fig. 4). Winter Q to the Baltic Sea increases while summer Q decreases. The spring flood peak is reduced for all scenarios. This is partly due to decreased snow storage and earlier snow melt as a result of the higher temperatures, particularly in the north, but also due to changes in the seasonal precipitation distribution. All projections had similar spring and summer $\mathrm{Q}$, but results varied between projections over autumn and winter. The A2, $\mathrm{A}_{1} \mathrm{~B}_{1}$ and Hadley $\mathrm{A} 1 \mathrm{~B}$ projections no longer had a significant spring flood peak, instead peak flows are observed between January and February indicating less winter snow storage. This effect was less pronounced for the $\mathrm{A}_{1} \mathrm{~B}_{3}$ projections at both $25 \mathrm{~km}$ and $50 \mathrm{~km}$.

Changes in Q to the six main Baltic Sea drainage basins vary in magnitude and in a few cases sign (Fig. 5). Increases to Q from the northern basins (Gulf of Bothnia and Bothnian Sea) are seen for all scenarios, generally a result of the increased precipitation to this region. Changes to the Baltic Proper are consistently small $(<5 \%)$ across all scenarios and vary in direction of change. 

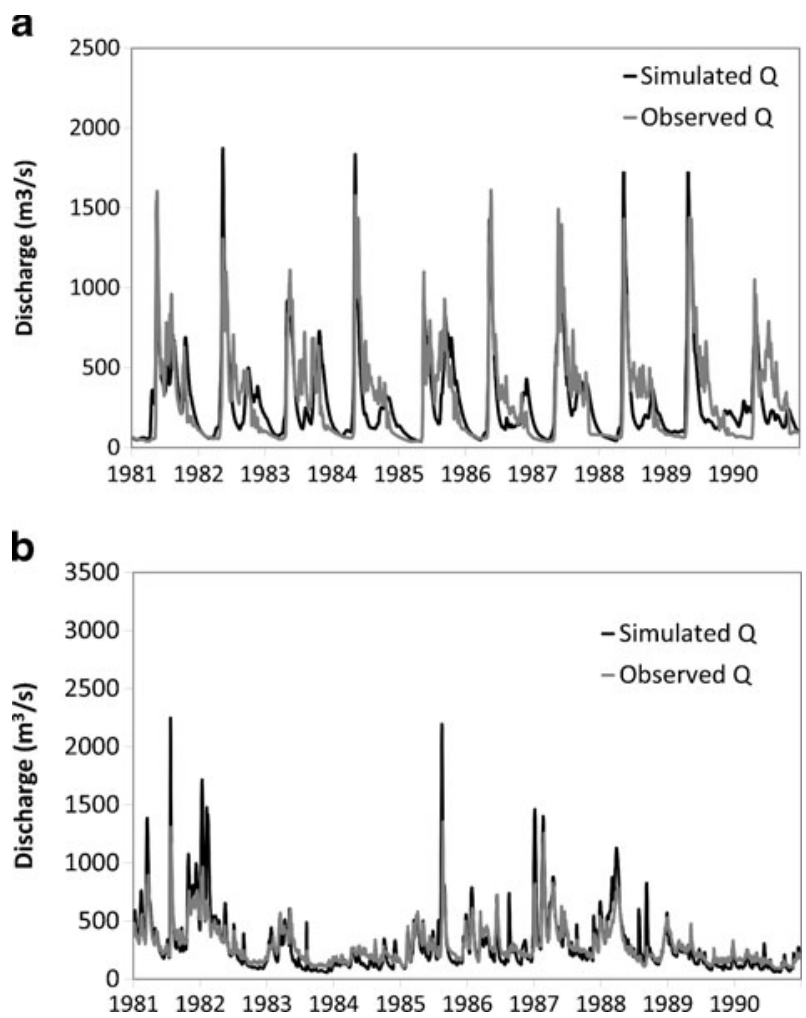

Fig. 2 Observed and simulated time-series of discharge for 2 averagely performing rivers in the model (a) Kalix River, Northern Sweden, (b) Oder River, German/Polish border

The other basins (Kattegat, Gulfs of Riga and Finland) show small to medium increases for most scenarios with the exception of the $50 \mathrm{~km} \mathrm{~A} \mathrm{~B}_{3}$ projection which indicated a decrease in $\mathrm{Q}$.

\section{Discussion}

This study and most other published projections of future Q to the Baltic Sea indicate an overall increase in Q at the end of next century (Hagemann et al. 2012; Meier et al. 2006; Graham 2004; Hagemann and Dumenil 1999; Meleshko et al. 2004; IPCC 2001), with the exception of a statistical downscaling study (Hansson et al. 2011). This study indicates a dampened seasonal variation of Q, also predicted by Graham (2004); however in this study some projections indicate only a weakened spring flood peak, while others indicate no spring flood. New results are seen for the changes in discharge to the Baltic Proper, the largest of the sea basins, as compared to a previous study which indicated decreases in Q to the Baltic Proper ( -5 to $-30 \%$, Graham 2004); here decreases were only seen for the $50 \mathrm{~km} \mathrm{~A} 1 \mathrm{~B}_{3}$ projection.

\subsection{Uncertainties}

Uncertainties can be divided into methodological uncertainties which come from the methodology of the study and external uncertainties which arise from not being able to predict 
Table 2 Description of scenario for each run and analysis of DBS corrected mean precipitation for those runs (1980 to 2004)

\begin{tabular}{|c|c|c|c|c|c|c|c|}
\hline $\begin{array}{l}\mathrm{RCM} \\
\text { resolution }\end{array}$ & Run & $\begin{array}{l}\text { Raw mean } \\
\text { annual basin } \\
\text { precipitation } \\
(\mathrm{mm})\end{array}$ & $\begin{array}{l}\mathrm{RE}(\%) \text { in } \\
\text { raw } \mathrm{RCM} \\
\text { precipitation }\end{array}$ & $\begin{array}{l}\text { Adjusted } \\
\text { mean annual } \\
\text { basin } \\
\text { Precipitation } \\
\text { (mm) }\end{array}$ & $\begin{array}{l}\mathrm{RE}(\%) \text { in } \\
\text { adjusted } \\
\text { precipitation }\end{array}$ & $\begin{array}{l}\text { Mean } \\
\text { annual } \\
\text { basin } \\
\text { discharge } \\
\left(\mathrm{m}^{3} / \mathrm{s}\right)\end{array}$ & $\begin{array}{l}\mathrm{RE}(\%) \text { in } \\
\text { discharge }\end{array}$ \\
\hline $11 \mathrm{~km}$ & $\begin{array}{c}\text { ERAMESAN } \\
\text { Hindcast }\end{array}$ & 631 & na & 631 & na & 15609 & na \\
\hline $50 \mathrm{~km}$ & RCA3E5A1B ${ }_{3 *}$ & 903 & $43 \%$ & 652 & $3.4 \%$ & 15822 & $1.4 \%$ \\
\hline $25 \mathrm{~km}$ & RCAOE $5 \mathrm{~A}_{1} \mathrm{~B}_{3} *$ & 901 & $43 \%$ & 638 & $1.0 \%$ & 14677 & $-6.0 \%$ \\
\hline $25 \mathrm{~km}$ & $\mathrm{RCAOE} \mathrm{A}_{1 \mathrm{~B}_{1}} *$ & 886 & $40 \%$ & 630 & $-0.1 \%$ & 14569 & $-6.7 \%$ \\
\hline $25 \mathrm{~km}$ & RCAOH3A1B & 875 & $39 \%$ & 610 & $-3.3 \%$ & 14982 & $-4.0 \%$ \\
\hline $25 \mathrm{~km}$ & RCAOE5A2 & 794 & $26 \%$ & 625 & $-1.0 \%$ & 14979 & $-4.0 \%$ \\
\hline
\end{tabular}

Relative errors are calculated as compared to the hindcast mean precipitation and discharge, respectively

* Refers to differing initial conditions in the GCM

anthropogenic behaviour in the future (i.e. emissions scenarios, land-use, and demographic scenarios). Here, only a small part of the external uncertainties are addressed by taking into account two emission scenarios with similar emissions development: the A1B and the A2 scenarios. The difference between these emissions scenario runs was smaller than the differences between the different GCM realisations of the same scenario (Table 3), i.e. the difference between the RCAOE5 $\mathrm{A} 2$ and $\mathrm{A}_{1} \mathrm{~B}_{1}$ runs is much smaller than the difference between the two realisations of the scenario RCAOH3A1B $\left(\mathrm{A}_{1} \mathrm{~B}_{1}\right.$ and $\left.\mathrm{A}_{1} \mathrm{~B}_{3}\right)$ indicating that uncertainties from GCMs (methodological) are also significant. Nevertheless, this addresses only a small part of the emissions uncertainty.

Methodological uncertainties can be divided into those from the different GCM/RCMs (i.e. uncertainties in climate models) and those from the methodology described in this study. Here the climate projections were produced using two different GCMs and two different RCMs. Additionally, one of the GCMs was forced using two different initial conditions, resulting in different realisations of the climate. This provides the opportunity to examine the effects of varying GCMs, (ECHAM5 and Hadley3) the internal variability of the ECHAM5 GCM (A1B 1 and $\mathrm{A}_{1} \mathrm{~B}_{3}$ ) and the effect of the oceanographic coupling of the RCM (RCAO and RCA3).

Compared to other uncertainties, the effect of the oceanographic coupling of the RCM on total Q to the Baltic Sea was small (note however, the larger RCM grid resolution). Comparing the ECHAM5 $\mathrm{A}_{1} \mathrm{~B}_{3}$ scenario regionally downscaled by the uncoupled RCA3 model at $50 \mathrm{~km}$ and the coupled RCAO model at $25 \mathrm{~km}$ showed very similar estimates of changes to total Q (Table 3), almost the same changes to the seasonal pattern of Q (Fig. 4), but some differences in changes to $\mathrm{Q}$ for the southern subbasins of the Baltic Sea (Fig. 5) where projected changes were small but varied in direction (sign) between the RCAO and RCA3 scenarios.

The effect of the internal variability from the ECHAM5 GCM was large with the RCAOE5A1B $\mathrm{B}_{1}$ run projecting a $12 \%$ increase in $\mathrm{Q}$ and the RCAOE5A1B $\mathrm{B}_{3}$ run projecting only a $3 \%$ increase in total Q (Table 3 ). Hence, internal variability within a single GCM is shown to be a significant contributor to methodological uncertainty. Between these two runs, there were large differences in the spatial and temporal distributions of runoff and discharge (Figs. 4 and 5), a result of differences in how these projections realised the spatial and temporal distributions of precipitation and temperature. 

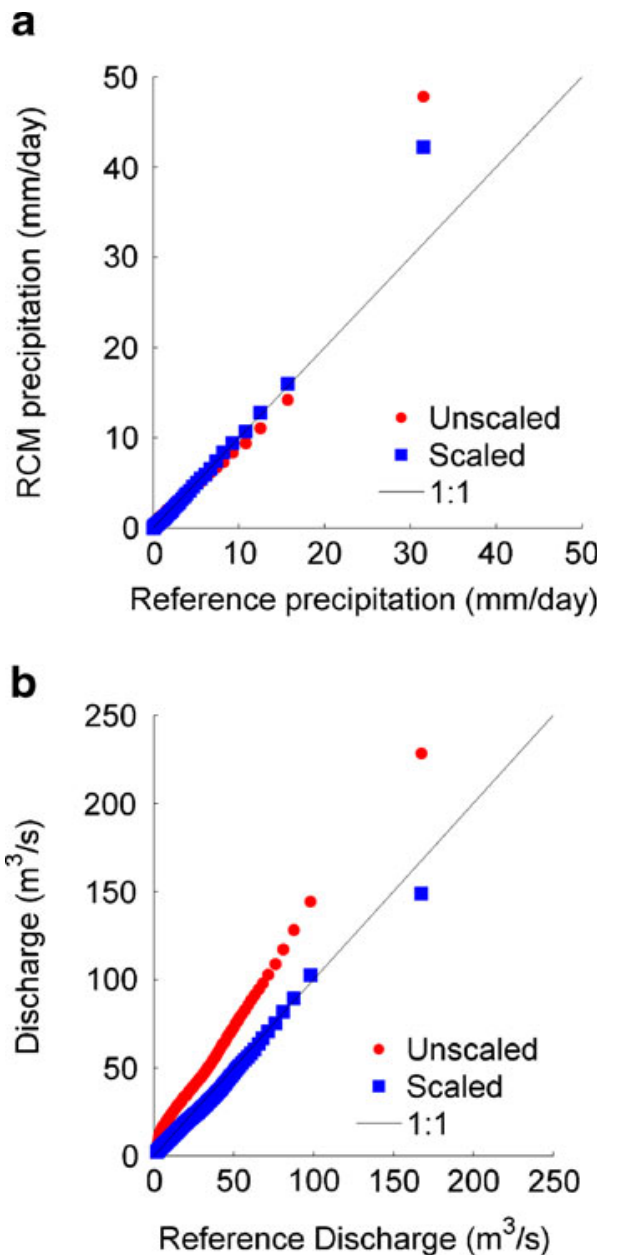

Fig. 3 Comparison of scaled and unscaled percentiles for the DBS adjusted RCAO_E5 A1B 3 projection for (a) the total precipitation for the Baltic Sea basin, and (b) the total discharge to Baltic Sea. (reference precipitation is from ERAMESAN and reference discharge is the discharge simulated using the reference precipitation)

Table 3 Simulated mean annual discharge to the Baltic Sea for the reference period (1971 to 2000), a future period (2071 to 2100) and the simulated change in discharge (absolute and relative) for each scenario

\begin{tabular}{lllll}
\hline Description & $\begin{array}{l}\text { Mean discharge } \\
\left(\mathrm{m}^{3} / \mathrm{s}\right) \\
1971-2000\end{array}$ & $\begin{array}{l}\text { Mean discharge } \\
\left(\mathrm{m}^{3} / \mathrm{s}\right) \\
2071-2100\end{array}$ & $\begin{array}{l}\Delta \mathrm{Q} \\
\left(\mathrm{m}^{3} / \mathrm{s}\right)\end{array}$ & $\begin{array}{l}\Delta \mathrm{Q} \\
(\%)\end{array}$ \\
\hline RCA3E5A1B $_{3}$ & 15541 & 15648 & 108 & $1 \%$ \\
RCAOE5A1B $_{3}$ & 14584 & 15075 & 491 & $3 \%$ \\
RCAOE5A1B $_{1}$ & 14890 & 16717 & 1827 & $12 \%$ \\
RCAOH3A1B & 14647 & 16391 & 1744 & $12 \%$ \\
RCAOE5A2 & 15278 & 17449 & 2171 & $14 \%$ \\
Ensemble & Mean & & 1268 & $8 \%$ \\
\hline
\end{tabular}




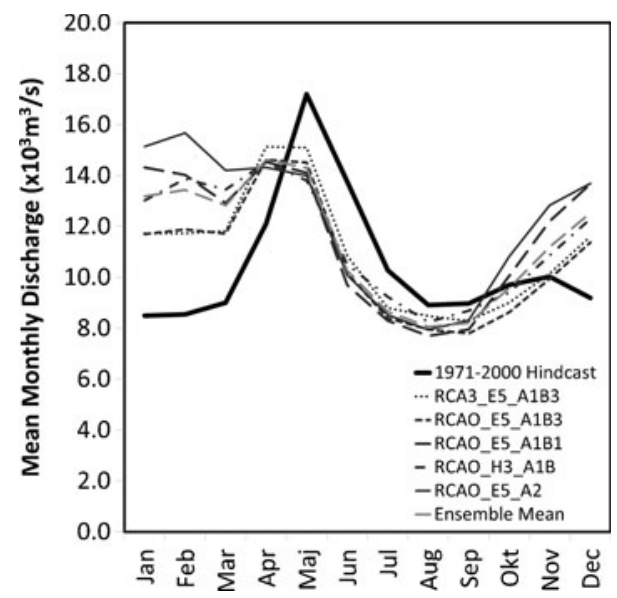

Fig. 4 Mean monthly discharge to the Baltic Sea, for period 1 (1971 to 2000) and all projections for period 2 (2071 to 2100)

The effect of varying the GCM was, in one case, smaller than the internal variability within the single $\mathrm{GCM}$, i.e. the RCAOE $5 \mathrm{~A}_{1} \mathrm{~B}_{1}$ run showed the same increase to total $\mathrm{Q}$ to the Baltic Sea as the RCAOH3A1B run (Table 3), similar temporal distributions of the future Q (Fig. 4), but some differences in the spatial distribution of the Q changes (Fig. 5). On the other hand, when comparing the other realisation of the A1B scenario (RCAOE5A1B $\left.{ }_{3}\right)$ to the Hadley A1B run, these differences are much larger. Nevertheless internal variability within GCMs is important to consider.

It is also important to examine internal uncertainties resulting from the hydrological impact modelling chain including the Balt-HYPE model itself and the BC. Even with the $\mathrm{BCs}$ made to the precipitation and temperature, biases in the simulated present day $\mathrm{Q}$ to the Baltic Sea range from $-7 \%$ to $+1 \%$ across all scenarios (Table 2 ). The magnitude of this

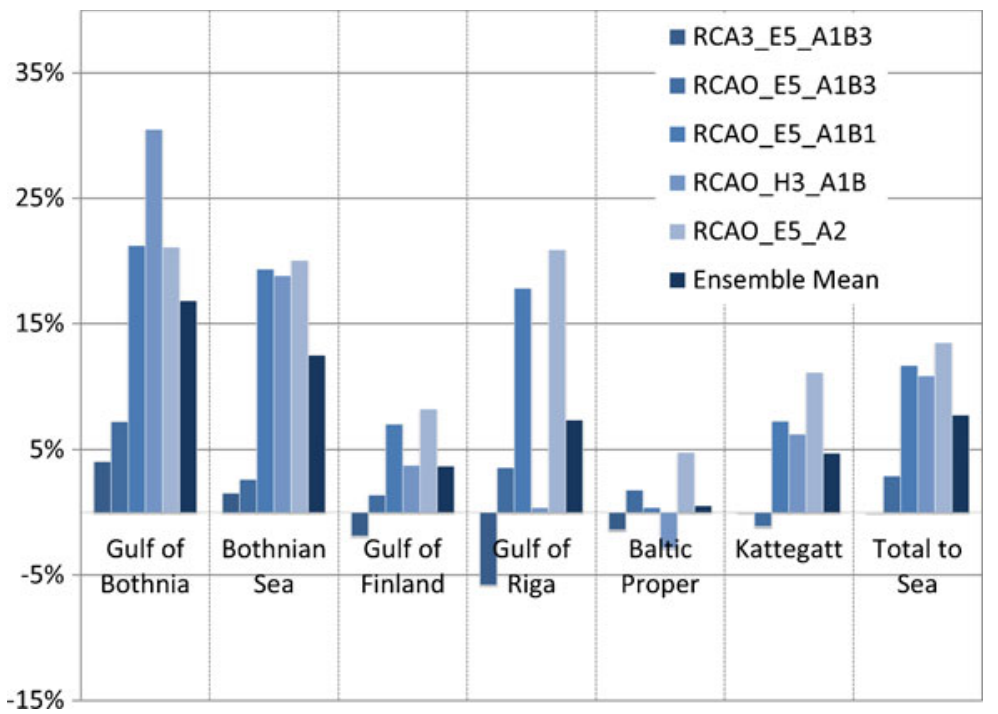

Fig. 5 Mean annual changes to discharge summarised for the 6 main drainage basins of the Baltic Sea 
error is similar to that of the predicted change (e.g. ensemble average $8 \%$ ). Although DBS does well to adjust the distribution of precipitation events, $\mathrm{BC}$ methods generally affect the magnitude of the changes to a variable projected by the raw climate model output and it is debatable whether this is preferable or not (see Berg et al. 2012; Li et al. 2010). Furthermore co-variation between variables can be affected and this affects, in particular, the magnitude of precipitation stored as snow because it is difficult to correct the timing of temperature events around the melting threshold (Dahné et al. 2013). Finally, the stationarity of the error model for $\mathrm{BC}$ is an assumption which warrants further investigation (e.g. Maraun et al. 2010). Quantile $\mathrm{BC}$ methods can capture the decadal variability included in the reference (tuning) period, but it is then assumed that the decadal variability outside of this period is sufficiently represented by the GCM. Other methods (e.g. Dunne et al. 2013) have corrected directly for the magnitude of decadal variability, but such methods are still dependent on the length of the reference period and don't correct for decadal variations in variable distribution.

There is also decadal variation in the ability of the Balt-HYPE model to correctly simulate Q. A 10-year running mean of volume errors was used to validate whether there were any significant temporal deviations in simulated volume to the Baltic Sea over the hindcast period (Fig. 6). The error in simulated volume varied by $9 \%$ : from $-7 \%(1979-1988)$ to $+2 \%$ (1998 to 2007) (validation stations vary for these periods due to data availability). This means that a simulated future change of $8 \%$ (the ensemble mean) may simply be a result of the limitations of the hydrological model's response to natural climatic variability, rather than a future climate change. There are therefore important uncertainties related to the HM used, also indicated by Hagemann et al. (2012) using HM ensembles.

Previous studies for the Baltic Sea (e.g. Meier et al. 2006) and other regions (e.g. Olsson et al. 2011; Van Vliet et al. 2012) indicate that they can give a measure of uncertainty simply by running a large ensemble of GCMs/RCMs. Uncertainties from $\mathrm{BC}$ procedures and $\mathrm{HM}$ are often ignored or assumed negligible. Until GCMs/RCMs can improve representations of precipitation and evapotranspiration, the need to use $\mathrm{BC}$ methods and HMs remains. It is strongly urged that the significant uncertainties due to $\mathrm{BC}$ and $\mathrm{HMs}$ are further explored and included in hydrological impact studies for all regions. Finally, to better predict the real uncertainty for changes in discharge to the Baltic Sea requires a larger ensemble of climate

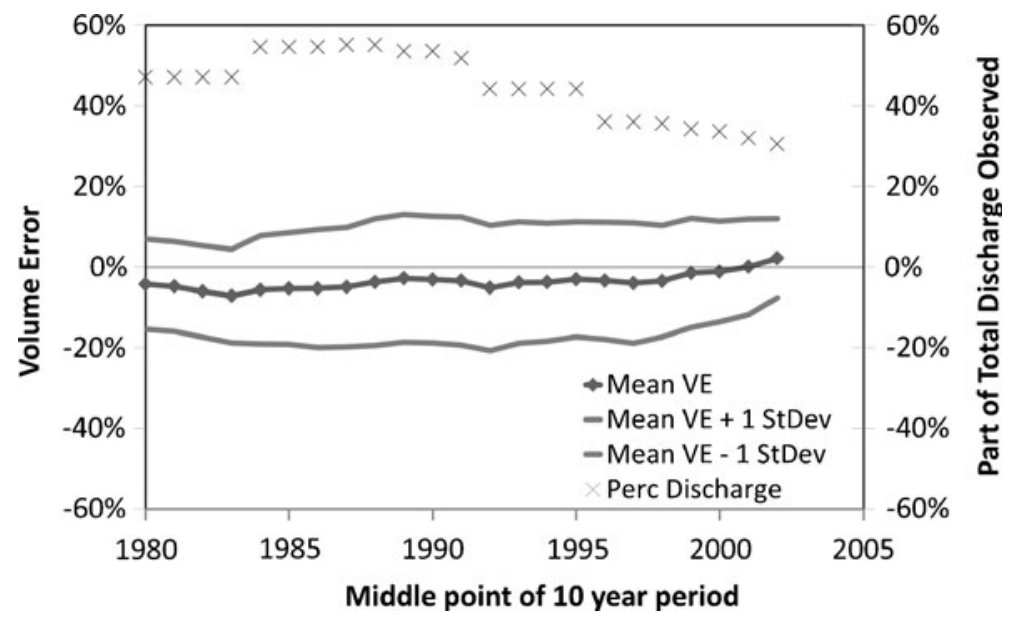

Fig. 6 Temporal evaluation of model showing running mean volume error for all river mouth stations and the mean $+/$ - standard deviation for all river mouths 
model runs representing other emissions storylines, as well as landuse and demographic changes which is yet to be assessed.

\section{Conclusions}

A high-resolution hydrological model simulating discharge across the entire Baltic Sea basin was used to simulate discharge to the Baltic Sea in a future climate. Results from a mini-ensemble of five simulations representing $\mathrm{A} 1 \mathrm{~B}$ and $\mathrm{A} 2$ emissions and various GCMs indicated that discharge to the Baltic Sea is likely to increase; however, the magnitude of predicted change is variable and highly uncertain, both due to the undersampling of emissions scenarios and GCMs, but also because it was shown that the projected changes can be of the same magnitude as the predictive uncertainty of the hydrological model and the bias-correction methodology. This uncertainty is not usually considered in impact studies but was shown to be important. Conclusions regarding the magnitude of change from this and previous studies are therefore not recommended and it is recommended that similar analyses of the BC method and HM used are included in all impact studies.

Qualitatively, it was concluded that discharge in the North of the basin is likely to increase, but it is still uncertain how discharge in the South of the basin will change. Averaged across the whole basin, increased discharges to the Baltic Sea in winter and decreased discharges in summer are likely at the end of this century. These conclusions reflect where all projections are in agreement and where results agree with previous studies based on larger ensembles.

Acknowledgments The authors would like to acknowledge funding from the BONUS program via the ECOSUPPORT project, the GEOLAND2 project funded by the European Union's FP7 program, the Hydroimpacts 2.0 project funded by the Swedish Research Council Formas and the assistance of Berit Arheimer, Johan Strömqvist, Johan Södling and Jörgen Rosberg in the preparation of data and model setup, of Phil Graham and Markus Meier for discussions of previous results and Jafet Andersson and anonymous reviewers for their revisions of the manuscript.

Open Access This article is distributed under the terms of the Creative Commons Attribution License which permits any use, distribution, and reproduction in any medium, provided the original author(s) and the source are credited.

\section{References}

Arnel NW (1999) A simple water balance model for the simulation of streamflow over a large geographic domain. J Hydrol 217(3-4):314-335

Arnold JG, Srinivasan R, Engel BA (1994) Flexible watershed configurations for simulating models. Hydrol Sci Technol 30(1-4):5-14

BACC Author Team (2008) Assessment of climate change for the Baltic Sea Basin. Springer

Berg P, Feldmann H, Panitz HJ (2012) Bias correction of high resolution regional climate model data. J Hydrol 448:80-92

Bergström S (1976) Development and application of a conceptual runoff model for Scandinavian catchments. Ph.D. Thesis. SMHI Reports RHO No. 7, Norrköping

Bergström S, Carlsson B (1994) River runoff to the Baltic Sea: 1950-1990. Ambio 23:280-287

BHDC (2009) Baltex Hydrological Data Centre. http:/www.smhi.se/sgn0102/bhdc/. Accessed 10 January 2009

Collins M, Booth B, Bhaskaran B, Harris GR, Murphy JM et al (2010) Climate model errors, feedbacks and forcings: a comparison of perturbed physics and multi-model ensembles. Clim Dyn 36(9):1737-1766 
Dahné J, Donnelly C, Olsson J (2013) Post-processing of climate projections for hydrological impact studies, how well is reference state preserved? Proceedings of IAHS-IAPSO-IASPEI Assembly, Gothenburg, Sweden, July 2013 (IAHS Publ. 2013 in press)

Dunne JP, Stouffer RJ, John JG (2013) Reductions in labour capacity from heat stress under climate warming. Nat Clim Chang 3:563-566

Fowler HJ, Blenkinsop S, Tebaldi C (2007) Linking climate change modelling to impacts studies: recent advances in downscaling techniques for hydrological modelling. Int J Climatol 27:1547-1578

Gao Y, Vano J, Zhu C, Lettenmaier DP (2011) Evaluating climate change over the Colorado River basin using regional climate models. J Geophys Res 116, D13104. doi:10.1029/2010JD015278

GLC (2009) Global Landcover 2000. http://ies.jrc.ec.europa.eu/global-land-cover-2000 Accessed 10 January 2009

Graham LP (2004) Climate change effects on river flow to the Baltic Sea. Ambio 33(4-5):235-241

Graham LP, Hagemann S, Jaun S, Beniston M (2007) On interpreting hydrological change from regional climate models. Clim Chang 81:97-122

GRDC (2009). Global Runoff Data Center http://www.bafg.de/GRDC/EN/Home/homepage_node.html Accessed 10 January 2009

Hagemann S, Dumenil L (1999) Application of a global discharge model to atmospheric model simulations in the BALTEX region. Nord Hydrol 30:209-230

Hagemann S, Göttel H, Jacob D, Lorenz P, Roeckner E (2009) Improved regional scale processes in projected hydrological changes over large European catchments. Clim Dyn 32:767-781

Hagemann S et al (2012) Climate change impact on available water resources obtained using multiple global climate and hydrology models. Earth Syst Dynam Discuss 3:1321-1345, www.earth-syst-dynamdiscuss.net/3/1321/2012/

Hansson D, Eriksson C, Omstedt A, Chen D (2011) Reconstruction of river runoff to the Baltic Sea, AD 1500-1995. Int J Climatol 31:696-703

Hay LE, McCabe GJ (2010) Hydrologic effects of climate change on the Yukon River Basin. Clim Chang 100(3-4):509-523

Hurkmans RTWL, Terink W, Uijlenhoet R, Torfs PJJF, Jacob D, Troch PA (2010) Changes in streamflow dynamics in the Rhine basin under three high-resolution climate scenarios. J Clim 23:679-699

IPCC (2001) Climate Change 2001: impacts, adaptation and vulnerability. Contribution of Working Group II to the Third Assessment Report of the Intergovernmental Panel on Climate Change. Cambridge University Press, Cambridge New York

Jansson A, Persson C, Strandberg G (2007) 2D meso-scale re-analysis of precipitation, temperature and wind over Europe - ERAMESAN Time period 1980-2004. SMHI Reports: Meteorology and climatology no. 112, SMHI, Norrköping

JRC (2006) European Soils Database. http://eusoils.jrc.ec.europa.eu/ESDB_Archive/ESDB/index.htm. Accessed 5 February 2009

Jungclaus JH, Botzet M, Haak H, Keenlyside N, Luo J-J et al (2006) Ocean circulation and tropical variability in the coupled ECHAM5/MPI-OM. J Clim 19:3952-3972

Kjellström E, Nikolin G, Hansson U, Strandberg G, Ullerstig A (2010) 21st century changes in the European climate: uncertainties derived from an ensemble of regional climate model simulations. Tellus $63 \mathrm{~A}(1): 24$ 40. doi:10.1111/j.1600-0870.2010.00475

Kling H, Fuchs M, Paulin M (2012) Runoff conditions in the upper Danube basin under an ensemble of climate change scenarios. J Hydrol 424-425:264-277

Li H, Sheffield J, Wood EF (2010) Bias correction of monthly precipitation and temperature fields from Intergovernmental Panel on Climate Change AR4 models using equidistant quantile matching. J Geophys Res 115, D10101. doi:10.1029/2009JD012882

Liang X, Lettenmaier DP, Wood EF, Burges J (1994) A simple hydrologically based model of land surface water and energy fluxes for GSMs. J Geophys Res 99(D7):14415-14428

Lindström G, Pers CP, Rosberg R, Strömqvist J, Arheimer B (2010) Development and test of the HYPE (Hydrological Predictions for the Environment) model - A water quality model for different spatial scales. Hydrol Res 41:295-319

Maraun D et al (2010) Precipitation downscaling under climate change: Recent developments to bridge the gap between dynamical models and the end user. Rev Geophys 48. RG3003

Meier HEM, Kjellström E, Graham LP (2006) Estimating uncertainties of projected Baltic Sea salinity in the late 21st century. Geophys Res Lett 33:4pp. doi:10.1029/2006g1026488

Meier HEM, Höglund A, Döscher R, Andersson H, Löptien U, Kjellström E (2011) Quality assessment of atmospheric surface fields over the Baltic Sea of an ensemble of regional climate model simulations with respect to ocean dynamics. Oceanologia 53:193-227 
Meleshko VP, Kattsov VM, Govorkova VA, Malevsky-Malevich SP, Nadezhina ED, Sporyshev PV (2004) Anthropogenic climate changes in Northern Eurasia in the 21st century. Russ Meteorol Hydrol 7:5-26

Nakicenovic N, Swart R (eds) (2000) Special report on emissions scenarios. In A Special Report of Working Group III of the Intergovernmental Panel on Climate Change. Cambridge University Press, Cambridge, United Kingdom and New York, NY, USA, 599

Olsson J, Yang W, Graham LP, Rosberg J, Andréasson J (2011) Using an ensemble of climate projections for simulating recent and near-future hydrological change to lake Vänern in Sweden. Tellus A 63:126-137

Omstedt A et al (2012) Future changes of the Baltic Sea acid-base (pH) and oxygen balances. Tellus B 64:19586

Piani C, Haerter JO, Coppola E (2010) Statistical bias correction for daily precipitation in regional climate models over Europe. Theor Appl Climatol 99(1-2):187-192

Strömqvist J, Arheimer B, Dahné J, Donnelly C, Lindström G (2012) Water and nutrient predictions in ungauged basins - Set-up and evaluation of a model at the national scale. Hydrol Sci J 57(2):229-247

Themeß1 MJ, Gobiet A, Leuprecht A (2010) Empirical-statistical downscaling and error correction of daily precipitation from regional climate models. Int J Climatol 31(10):1530-1544

USGS (2000) Hydro1k Elevation Derivative Database. http:/edc.usgs.gov/products/elevation/gtopo30/hydro/ index.html. Accessed 16 February 2009.

Van Vliet MTH, Yearsley JR, Ludwig F, Vögele S, Lettenmaier DP, Kabat P (2012) Vulnerability of U.S. and European electricity supply to climate change. Nat Clim Chang 2(9):676-681

Vörösmarty CJB et al (1989) Continental scale models of water balance and fluvial transport: an application to South America, Global Biogeochem. Cycles 3(3):241-265

Yang W, Andreásson J, Graham LP, Olsson J, Rosberg J, Wetterhall F (2010) Distribution-based scaling to improve usability of regional climate model projections for hydrological climate change impacts studies. Hydrol Res 41(3-4):211-228 